\title{
Manejo de Resíduos Sólidos Perigosos e Sobras Alimentares em Meios de Hospedagem
}

\author{
Handling of Hazardous Sølid Waste and Alimentary \\ Leftovers in Lodging Means
}

\section{Patrícia P. P. Cesa ${ }^{1}$ \\ Suzana Maria de Conto ${ }^{2}$}

\begin{abstract}
RESUMO: A constante geração de resíduos sólidos e sobras alimentares é um grande problema para os empreendimentos turísticos e hoteleiros. O turismo, visto como uma importante atividade econômica resultante do movimento em massa de pessoas, necessita de um planejamento eficaz e integrado com a comunidade nas ações voltadas ao gerenciamento de seus resíduos sólidos. O presente estudo analisa as informações de 12 sujeitos entrevistados sobre o manejo de resíduos sólidos perigosos e sobras alimentares geradas no âmbito de seis meios de hospedagem do município de Canela - RS. Os resultados indicam que os meios de hospedagem necessitam planejar e implantar programas de gerenciamento de resíduos sólidos.
\end{abstract}

PALAVRAS-CHAVE: resíduos sólidos; manejo de resíduos sólidos perigosos; sobras alimentares; meios de hospedagem; turismo.

ABSTRACT: The constant generation of solid waste and alimentary leftovers are a great problem for the tourist and hotel enterprises. The tourism seen as an important economic activity that results in the movement of people's mass, needs an effective planning and integrated with the community

1. Mestre em Turismo pela Universidade de Caxias do Sul. Técnica Administrativa da Assessoria de Assuntos Interinstitucionais e Internacionais - UCS. Contato: Rua Francisco Getúlio Vargas, 1130 95070-560 - Caxias do Sul-RS; e-mail: PPPCesa@ucs.br.

2. Engenheira Química, Doutora em Educação pela Universidade Federal de São Carlos. Professora no Departamento de Engenharia Química e no Mestrado em Turismo da Universidade de Caxias do Sul. Contato: Rua Francisco Getúlio Vargas, 1130 - 95070-560 - Caxias do Sul-RS; e-mail: smcmande@ucs.br. 
in the actions returned to the management of its solid waste. The present study analyzes the information of 12 subjects on the handling of hazardous solid waste and alimentary leftovers generated in the frame of six lodging means from Canela-RS. The results indicate that the lodging means need to planning and to implant programs of management of solid waste.

KEYWORDS: solid waste; handling of hazardous solid waste; alimentary leftovers; lodging means; tourism.

\section{Introdução}

A constante geração de resíduos sólidos torna-se um grande problema para os empreendimentos turísticos. O turismo, visto como uma importante atividade econômica resultante do movimento em massa de pessoas, necessita de um planejamento eficaz e integrado com a comunidade nas ações voltadas ao gerenciamento de seus resíduos sólidos.

É importante, ao analisar dados pertinentes ao planejamento do turismo, relacioná-los à situação nacional do saneamento ambiental. O colapso do saneamento ambiental no Brasil é perceptível. A falta de água potável e de esgoto sanitário é responsável por $80 \%$ das doenças e $65 \%$ das internações hospitalares (D’Almeida; Vilhena, 2000). Além disso, 90\% dos esgotos domésticos e industriais são despejados sem qualquer tratamento nos mananciais de água.

O debate sobre o tratamento e a disposição de resíduos sólidos urbanos ainda é bastante negligenciado pelo poder público. A maioria das cidades brasileiras, aí incluídas as de vocação turística, ainda não conta com sistema de aterro sanitário para a disposição final de resíduos sólidos. Dados divulgados pelo Instituto Brasileiro de Geografia e Estatística - IBGE, em sua Pesquisa Nacional de Saneamento Básico (2002), revelam que, no Brasil, são produzidas diariamente 125.281 toneladas de resíduos, sendo $47,1 \%$ destinadas a aterros sanitários, 22,3\% a aterros controlados e 30,5\% a lixões. Porém, se esta mesma análise for feita em termos de número de municípios, o resultado não se apresenta tão favorável: $63,6 \%$ utilizam lixões e 32,2\% aterros "adequados" (13,8\% sanitários, 18,4\% aterros controlados).

Como esses problemas estão relacionados ao turismo? Que destino é dado aos resíduos sólidos gerados nos meios de hospedagem? Os programas desenvolvidos para o turismo prevêem planos de gerenciamento de resíduos sólidos que contemplem a geração, a coleta, o reaproveitamento, o tratamento e a disposição final? Essas, entre outras perguntas, merecem uma análise e resposta por parte dos agentes responsáveis pelo turismo e pelos meios de hospedagem dos municípios.

Cabe destacar que medidas importantes vêm sendo tomadas visando incentivar a hotelaria brasileira, seus funcionários e hóspedes a uma mudança de cultura que consolide uma postura ambientalmente correta.

Opresidente da Associação Brasileira da Indústria de Hotéis $(\mathrm{ABIH}), \mathrm{Hercu}-$ lano Iglesias, apresentou, no ano de 2001, na embaixada do Brasil em Londres, o conceito do projeto ambiental da entidade, denominado "Hóspedes da Natureza". Esse projeto foi inspirado no International Hotel Environment Initiative (IHEI), programa criado na Inglaterra, após a conferência Eco-92, realizada no Rio de Janeiro. Segundo o consultor da $\mathrm{ABIH}$, o manual de práticas ambientais foi adaptado à hotelaria brasileira e "tropicalizado", não devendo impor muitas dificuldades de adaptação aos hotéis do país (ABIH-RS, 2001).

Outra ação promovida pela $\mathrm{ABIH}$ em parceria com a Embratur refere-se ao novo sistema de classificação hoteleira. A nova matriz, elaborada pela própria $\mathrm{ABIH}$, mantém o sistema de classificação por estrelas (luxo: cinco estrelas; superior: quatro estrelas; turístico: três estrelas; econômico: duas estrelas e simples). Ela é composta por 270 itens e apresenta um capítulo destinado às questões ambientais, abordando temas como racionamento, preservação, redução de consumo de água, armazenamento de energia e resíduos sólidos. No que tange aos resíduos sólidos, são apresentadas medidas relacionadas à geração, armazenagem e destinação (ABIH, 2001).

Devido à escassez de estudos sistematizados sobre a geração e o manejo de resíduos sólidos gerados no âmbito dos meios de hospedagem, é importante analisar as contribuições de Mandelli (1997). O autor, em seu estudo sobre variáveis que interferem no comportamento da população urbana no manejo de resíduos sólidos domésticos no âmbito das residências, afirma que lidar com esses resíduos exige esforços integrados e multiprofissionais. $\mathrm{O}$ autor destaca, ainda, que diferentes áreas do conhecimento podem contribuir para a minimização dos problemas e das dificuldades enfrentadas pela população urbana no manejo de tais resíduos: a engenharia civil, a engenharia de produção, a engenharia de materiais, a arquitetura, o marketing, a administração, a psicologia e a ecologia, entre outras. Esses estudos, desenvolvidos no âmbito das residências, também podem ser examinados no âmbito dos meios de hospedagem, auxiliando no entendimento das relações que se estabelecem na geração de resíduos sólidos e no comportamento de funcionários e hóspedes em relação aos mesmos.

Os estudos realizados por Mandelli (1997) salientam a importância da identificação das situações de manejo de resíduos sólidos no âmbito da fonte geradora, no sentido de auxiliar na compreensão dos problemas relacionados ao manejo 
e destino final dos mesmos. Sendo os resíduos sólidos produtos resultantes das atividades diárias desenvolvidas nos meios de hospedagem, considera-se relevante o seu estudo nos processos de investigação científica na área do turismo.

Os problemas relacionados aos resíduos sólidos gerados nos meios de hospedagem também suscitam questões que parecem exigir estudos e respostas de certa profundidade: 1) Que fatores influem na geração de resíduos sólidos? 2) Como o comportamento dos prestadores de serviço no turismo interfere no manejo de resíduos sólidos ainda na fonte geradora? 3) Como a formação de recursos humanos pode contribuir para aperfeiçoar o gerenciamento dos resíduos sólidos nos meios de hospedagem? 4) Quais são as situações de manejo de resíduos sólidos nos meios de hospedagem?

O presente estudo pretende analisar as informações de que dispõem os sujeitos do objeto pesquisado, referentes ao "fenômeno resíduos sólidos", sua geração, seu manejo, seu tratamento e destino final, com ênfase para os resíduos perigosos e sobras alimentares geradas em seis meios de hospedagem, em particular.

\section{Meios de Hospedagem e a Geração de Resíduos Sólidos}

Rocha, Junco e Gonzáles (2000: 375) oferecem contribuições importantes sobre a gestão ambiental nas empresas turísticas. Os autores apresentam os princípios apontados na Agenda 21 para a indústria do turismo, relacionados ao desenvolvimento sustentável.

Para a hotelaria, Rues (1995: 83) apresenta a Declaração de Nuremberg (Alemanha) para uma administração consciente do meio ambiente em uma indústria de hotelaria e de restaurantes. A declaração contém deż metas para hotéis e restaurantes, que orientam e aplicam uma administração eficiente e consciente em prol do meio ambiente e do consumo de energia.

Importantes contribuições de Rues (1995) e Goeldner, Ritchie e McIntosh (2002) estão relacionadas a programas de minimização e reciclagem de resíduos sólidos nas redes hoteleiras internacionais, demonstrando o compromisso dos hotéis com a preservação do meio ambiente.

No entendimento de Rues (1995), a hotelaria representa um papel fundamental no desenvolvimento das destinações turísticas. Ela pode contribuir substancialmente para a conservação dos recursos naturais, culturais e tradicionais, dentro de um planejamento visionário e em consonância com o novo conceito de turismo, especializado na conscientização das comunidades internacionais.

O autor defende que, desde o seu desenvolvimento global, a partir da década de 1950, a atividade hoteleira tornou-se a coluna vertebral do turismo e vem ocupando uma posição de liderança. O autor afirma que esta posição, especialmente no que diz respeito à conservação do meio ambiente, constitui o maior desafio para os hoteleiros da atualidade.

Ainda de acordo com Rues (1995), o mau uso - ou o uso inadequado - de materiais, e os resíduos das indústrias de serviço converteram-se no "inimigo número um" do meio ambiente, e produziram uma das maiores perdas econômicas das duas últimas décadas. No âmbito da atividade turística, a hotelaria é o setor que está produzindo a maior quantidade de resíduos.

De acordo com Molina (1998: 69), genericamente os meios de hospedagem são responsáveis pela poluição de recursos naturais imprescindíveis ao turismo:

O equipamento hoteleiro e de serviços de apoio, assim como as residências privadas, são as principais fontes das descargas residuárias nos mares - e na terra -, nos complexos turísticos.

Abreu (2001:58) considera a atividade hoteleira como potencial impactante do meio ambiente quando se refere "à utilização dos recursos naturais como água e energia; (...) ao lixo que é gerado nesses locais, aos equipamentos, aos produtos de uso diário, aos efluentes líquidos misturados com detergentes e outros dejetos orgânicos, e a tantos outros fatores (...)".

Swarbrooke (2000) defende que as empresas constituintes da atividade turística - nelas incluídas os meios de hospedagem - são estimuladas a agir de maneira responsável, principalmente por conta da consciência da importância que a qualidade ambiental representa para o futuro de seus negócios e do temor de ter suas atividades regulamentadas oficialmente, caso não tomem iniciativas voluntárias a fim de promover ações socioambientais responsáveis.

Instituições ligadas à atividade turística, em diversos países, sobretudo na Inglaterra, desenvolveram sistemas de gestão ambiental específicos para empreendimentos turísticos. Um desses sistemas, adaptado às condições brasileiras, deu origem ao Programa Hóspedes da Natureza, da Associação Brasileira da Indústria de Hotéis - ABIH.

No caso específico dos resíduos sólidos, o Programa Hóspedes da Natureza orienta os hoteleiros desde o levantamento dos tipos e das quantidades de resíduos gerados, formas de destinação final, e custos envolvidos até a verificação das possibilidades de reduzir, reutilizar e reciclar. Propõe, ainda, a implantação de um Plano de Ação e Monitoramento dos Resíduos Sólidos, incorporando desde sistemas de separação e triagem na fonte dos resíduos recicláveis até a eliminação do uso de produtos tóxicos, a composição da fração orgânica dos resíduos e a substituição de produtos descartáveis. 
Nos dias atuais, em que os conceitos de sustentabilidade e preservação ambiental vêm-se difundindo e consolidando, as empresas estão buscando desenvolver processos de produção mais apropriados a essa realidade de conscientização ecológica. As chamadas "tecnologias limpas" já são realidade em muitas áreas e, gradativamente, tenderão a disseminar-se ainda mais intensamente, inclusive nos campos do turismo e da hotelaria, conforme prevêem Lamprecht e Ricci (1997).

Para que se possa analisar dados e aspectos relacionados aos resíduos sólidos gerados no âmbito dos meios de hospedagem, é importante o entendimento dos termos comumente utilizados nos programas de gerenciamento desses resíduos.

Examinando diferentes contribuições sobre definições de resíduos sólidos, Lima (1995) afirma que defini-los não é tarefa fácil devido a inúmeros fatores ligados à sua origem e formação, como número de habitantes do local, área relativa de produção, variações sazonais, legislação, condições climáticas, hábitos, variações da economia, poder aquisitivo, nível educacional, tipo de equipamento de coleta, segregação na origem, sistematização da origem, disciplina e controle dos pontos produtores, leis e regulamentações específicas.

O mesmo autor comenta que "a identificação desses fatores é uma tarefa muito complexa e somente um intenso estudo, ao longo de muitos anos, poderia revelar informações mais precisas no que se refere à origem e à formação do lixo no meio urbano". Lima (1995) afirma, ainda, que "é comum definir como lixo todo e qualquer resíduo que resulte das atividades diárias do homem na sociedade”.

Mandelli (1997) apresenta diferentes contribuições para a definição de resíduos sólidos, comentando que não existe clareza sobre esse conceito na literatura nem sobre o termo lixo. Também comenta que a experiência individual (capacitação profissional) pode interferir na formulação de conceitos relacionados aos resíduos sólidos. Para efeito deste estudo, adotar-se-á como resíduos sólidos todos os produtos descartados diariamente resultantes da atividade de um meio de hospedagem.

Como gerenciamento de resíduos sólidos entende-se um conjunto articulado de ações normativas, operacionais, financeiras e de planejamento baseadas em critérios sanitários, ambientais, sociais, políticos, técnicos, educacionais, culturais, estéticos e econômicos para a geração, o manejo, o tratamento e a disposição final dos resíduos sólidos (Mandelli, 1997).

No sentido de melhor compreender as características dos resíduos gerados nos meios de hospedagem, é importante identificar as diferentes categorias de seus componentes - matéria orgânica putrescível, plástico, papel e papelão, vidro, metais ferrosos e não-ferrosos, pano, trapo, couro, borracha, madeira, pedra e contaminantes biológicos e químicos, entre outros -, conforme proposto por Mandelli (1997) e a classificação da Associação Brasileira de Normas Técnicas (ABNT, 1987):

- Classe I (Perigosos) - apresentam risco à saúde devido às suas propriedades de inflamabilidade, corrosividade, reatividade e radioatividade;

- Classe II (Não-Inertes) - apresentam propriedades como combustibilidade, biodegradabilidade ou solubilidade em água;

- Classe III (Inertes) - não possui nenhum de seus constituintes solubilizados em concentrações superiores aos padrões de potabilidade da água.

Cabe apresentar alguns exemplos de componentes encontrados nos resíduos sólidos, segundo suas diferentes categorias:

- matéria orgânica putrescível: sobras alimentares de origem animal e vegetal;

- plástico: sacos, sacolas, embalagens de refrigerante e de água;

- papel e papelão: caixas, revistas, jornais;

- vidro: garrafas de bebida, copos, pratos;

- metal ferroso: enlatados de produtos alimentício, palha de aço;

- metais não-ferrosos: latas de bebidas, fiação elétrica;

- madeira: caixas, lenha, tábuas;

- panos: peças de vestuário, pedaços de tecido;

- contaminantes químicos: pilhas, baterias, medicamentos e lâmpadas fluorescentes;

- contaminantesbiológicos:papel higiênico, cotonetes, algodão, curativos e preservativos.

A identificação desses componentes torna-se importante para examinar as ações que vêm sendo realizadas no âmbito dos meios de hospedagem em relação ao manejo de seus resíduos sólidos. O entendimento das diferentes frações que compõem a massa de resíduos sólidos permite planejar, implantar, operar e monitorar as etapas do gerenciamento desses resíduos (não gerar, minimizar, reaproveitar, tratar e dispor). 


\section{Metodologia}

\section{Características do município onde foi realizada a coleta de dados}

Canela, situada na Serra Gaúcha, a 830 metros acima do nível do mar, é um dos municípios com atuação turística mais destacada no estado do Rio Grande do Sul. Com uma população estimada em 35 mil habitantes e área de $252,9 \mathrm{~km}^{2}$, o seu maior apelo turístico é a Cascata do Caracol, queda d'água de 131 metros, situada junto ao parque de mesmo nome, e que dispõe de infra-estrutura que oferece lancheria, trilhas ecológicas, churrasqueiras e a sede do Projeto Lobo-Guará de preservação da natureza.

Além disso, o turista pode apreciar outras obras de arte da natureza, como o Pinheiro Grosso, o Parque da Ferradura e a Floresta Nacional do Ibama. A Catedral de Pedra, o Mundo a Vapor, a Fazenda Passo Alegre, o Castelinho e o Sítio da Mamãe Noel constituem outros atrativos turísticos da famosa cidade serrana.

O município de Canela conta, ainda, com o Núcleo Universitário de Canela (Nucan), da Universidade de Caxias do Sul. Junto ao núcleo está instalado o Hotel Escola, importante centro de aulas práticas e teóricas dos cursos de bacharelado em Turismo e de tecnologia em Hotelaria. O número de alunos supera 1.300, sendo o corpo docente formado por 80 professores. Em 23 anos de atuação, o Núcleo já formou aproximadamente 1.200 profissionais.

A rede hoteleira do município compõe-se de 52 estabelecimentos, entre hotéis e pousadas, totalizando 3.370 leitos. Segundo dados da Secretaria Municipal de Turismo, Canela recebeu, ao longo do ano de 2001, um fluxo de três milhões de turistas. Deste total, o montante mais expressivo concentra-se no período da alta temporada (mês de dezembro) durante a realização do Sonho de Natal. Outros eventos também contribuem para o afluxo turístico à cidade: a Chocofest, no período que antecede à Páscoa, e o Festival Internacional de Teatro de Bonecos, no mês de julho.

Canela possui $100 \%$ da área municipal com serviço de coleta seletiva, com uma periodicidade de três vezes por semana (segundas, quartas e sextas-feiras) para o "lixo orgânico" e uma vez por semana para o "lixo seco", cujo dia varia de acordo com o bairro. Em algumas ruas da cidade, localizadas no centro, existe uma programação de coleta especial, com uma periodicidade de três vezes por semana (segunda, quarta e sexta-feira) para o "lixo seco" e quatro vezes por semana (dias restantes) para o "lixo orgânico". Os resíduos sólidos da coleta regular são transferidos para o aterro sanitário do município. Os resíduos da coleta seletiva são conduzidos para uma central de triagem.

\section{Critérios para a seleção dos meios de hospedagem}

O município de Canela possui 52 meios de hospedagem, entre hotéis e pousadas. Para efetuar o levantamento das situações de manejo dos resíduos sólidos produzidos nos meios de hospedagem na cidade de Canela, optou-se por meios de hospedagem que representassem as categorias de classificação empregadas pela Embratur, constantes no artigo 12 do Regulamento e Matriz de Classificação dos Meios de Hospedagem e Turismo (Embratur; Inmetro, 1998). As categorias selecionadas foram: luxo (cinco estrelas); superior (quatro estrelas); turístico (três estrelas), econômico (duas estrelas) e simples (uma estrela). Para completar o estudo, foram feitas análises junto a uma pousada. Canela não dispõe de serviço de albergue.

\section{Critérios para a escolha dos sujeitos}

Para a determinação dos sujeitos a serem entrevistados nos meios de hospedagem selecionados para o estudo sobre o manejo de resíduos sólidos, foram escolhidos dois representantes das áreas que compõem a estrutura administrativa de hotéis e pousadas, a saber:

- área administrativa: representada pelo gerente geral;

- área de hospedagem ou governança: representada por camareiras.

\section{Procedimentos para a elaboração do roteiro de entrevista}

O roteiro de entrevista foi elaborado considerando as situações que caracterizam o manejo dos resíduos sólidos nos meios de hospedagem. As situações destacadas foram:

a) informação disponível sobre resíduos sólidos;

b) manejo dos resíduos sólidos perigosos (dispositivos existentes, local, espaço, dificuldades, responsabilidade no âmbito dos meios de hospedagem);

c) produção de resíduos sólidos;

d) segregação de resíduos sólidos;

e) destino de sobras alimentares, entre outros. 


\section{Resultados}

Destino de resíduos sólidos gerados no âmbito dos meios de hospedagem

Qual é o destino dos resíduos sólidos gerados nos meios de hospedagem? Os administradores desses meios conhecem esse destino?

As Tabelas 1 e 2 apresentam informações relacionadas ao destino dos resíduos sólidos gerados nos meios de hospedagem.

A Tabela 1 revela a distribuição de freqüências e porcentagens de indicações dos sujeitos sobre o destino dos resíduos sólidos e das sobras alimentares gerados nos meios de hospedagem. É possível observar que, entre os sujeitosgerente, $31,25 \%$ das indicações dão conta de que as sobras alimentares são destinadas ao "lixo orgânico". A segunda indicação mais freqüente é o encaminhamento para reciclagem, com um percentual de $25 \%$. Com $18,75 \%$, a informação "não sabe" foi indicada por três dos seis sujeitos-gerente (dos hotéis duas, três e quatro estrelas). A informação de que as sobras alimentares são doadas para instituições e pessoas carentes aparece com uma porcentagem de $12,50 \%$, tendo sido citada pelos gerentes dos meios de hospedagem categoria duas e cinco estrelas. $O$ gerente do meio de hospedagem categoria cinco estrelas afirmou que, duas vezes por semana, um caminhão passa para recolher as sobras alimentares geradas no meio de hospedagem, para posterior uso na alimentação de suínos pertencentes a uma instituição que trata da recuperação de dependentes químicos, localizada em um município vizinho. Posteriormente, esses suínos são abatidos e servem de alimento aos internos da instituição.

A informação "aterro", como destino dos resíduos sólidos, aparece com 6,25\% das indicações, bem como a informação de que "as sobras alimentares são separadas". Convém destacar que existe uma diferenciação na expressão sobras alimentares, pois ocorrem duas situações que ocorrem nos meios de hospedagem: existem as sobras alimentares que não foram totalmente consumidas pelos hóspedes, e existem as sobras alimentares excedentes, que foram produzidas a mais e nem sequer chegaram ao prato dos hóspedes. Este excedente, como prática freqüente em alguns meios de hospedagem, costuma servir de alimento para os próprios funcionários.

Entre os sujeitos-camareira, a informação de que as sobras alimentares são colocadas no "lixo orgânico" aparece com cinco indicações, perfazendo um total de $41,66 \%$ (hotéis uma estrela, duas estrelas, quatro estrelas, cinco estrelas e pousada). Houve quatro indicações relativas à informação "não sabe", com 33,33\% de freqüência (hotéis três estrelas, quatro estrelas, cinco estrelas e pousada). As informações "usina" e "terreno da prefeitura", como indicações de destino dos
Tabela 1. Distribuição de freqüências e porcentagens de indicações dos sujeitos sobre o destino dos resíduos sólidos e sobras alimentares nos diferentes meios de hospedagem

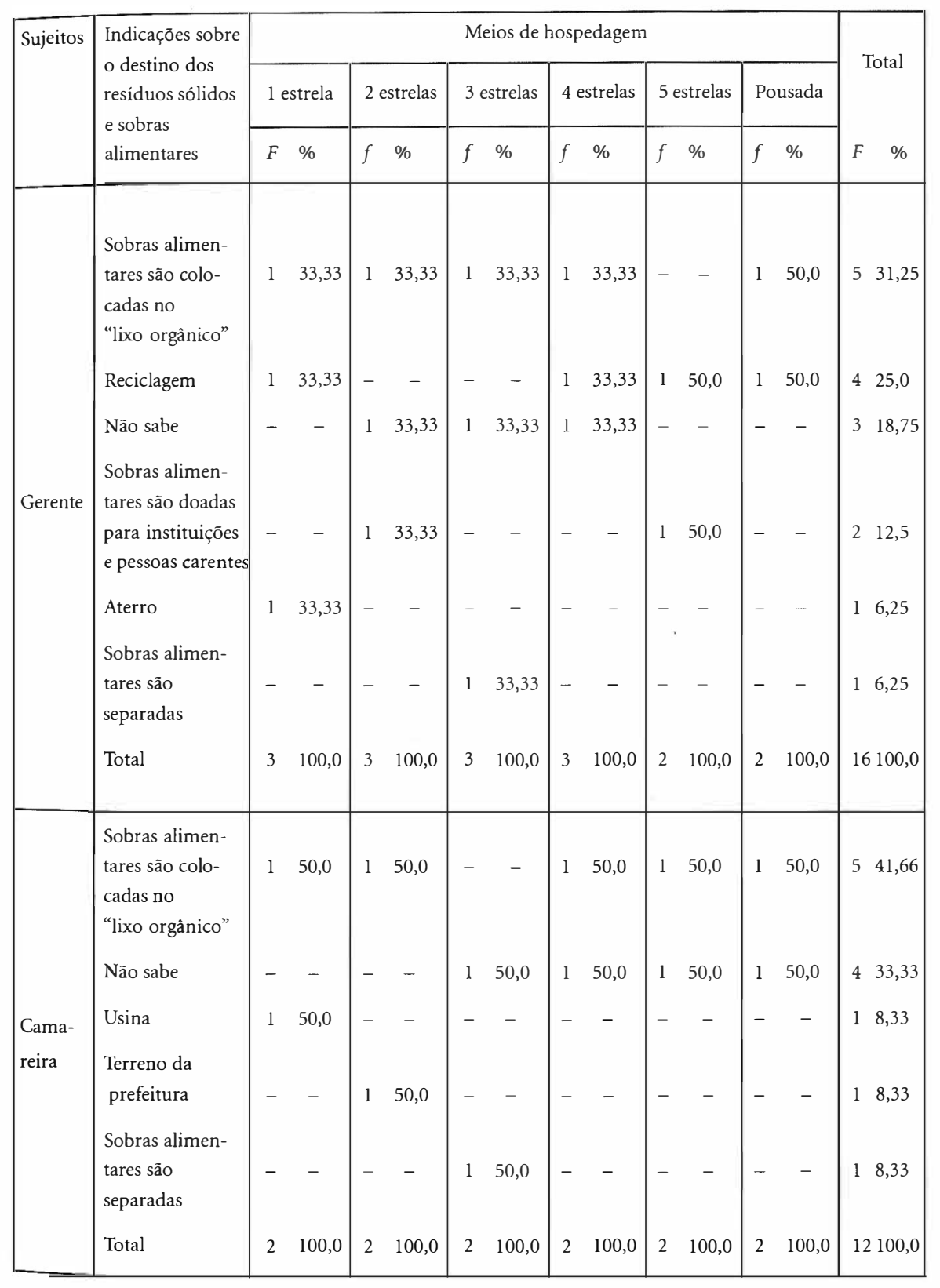

Fonte: Pesquisa de Campo (2003) 
resíduos sólidos, é de 8,33\% cada (hotéis uma estrela e duas estrelas). Apenas uma indicação $(8,33 \%)$, do hotel três estrelas, é referente a "sobras alimentares são separadas".

De posse dessas informações, é importante destacar a questão legal referente à doação de alimentos. Ficou claro que a prática de doar sobras alimentares vem sendo utilizada por um meio de hospedagem como forma de destino dos resíduos sólidos por ele gerados. Porém, existe uma legislação específica tratando desse tema, e que próibe esse tipo de conduta. De acordo com informações do serviço de Vigilância Sanitária do município de Caxias do Sul, com relação ao destino dos alimentos dos meios de hospedagem é importante lembrar a Lei Estadual no 6.503, de 22/12/1972, regulamentada pelo Decreto Estadual no 23.430 de 24/10/1974 (Rio Grande do Sul, 1972). O artigo 371 apresenta: "É proibido fornecer ao consumidor sobras ou restos de alimentos que já tenham sido servidos, bem como o aproveitamento das referidas sobras ou restos para a elaboração ou preparação de outros produtos alimentícios."

Também, cabe destacar o artigo 444 dessa Lei: "É proibido o uso de lixo "in natura" para servir como alimento a suínos e outros animais".

$\$ 1^{\circ}$ - Para efeitos deste artigo, admite-se na alimentação de suínos e outros animais o aproveitamento de resíduos de cozinha, desde que sejam mantidos e conduzidos em recipientes hermeticamente fechados e de uso exclusivo para esse fim, devendo estes ser previamente limpos e desinfetados, de acordo com as instruções da autoridade sanitária.

$\$ 2^{\circ}$ - Tratando-se de restos de comida de hospitais, o aproveitamento para a alimentação de suínos e outros animais só é permitido no caso de desinfecção pelo calor, realizada no próprio estabelecimento hospitalar.

Silva Jr. (1995) apresenta importantes contribuições sobre o controle higiênico-sanitário em alimentos, destacando as diferentes formas pelas quais se apresentam as sobras alimentares (sobras de alimentos não preparados, sobras de alimentos pré-preparados, sobras de alimentos prontos, sobras de alimentos distribuídos - restos).

Nesse contexto, é importante questionar: a) Qual é a produção das diferentes sobras de alimentos em meios de hospedagem? b) Como essas sobras são controladas? c) Qual o destino dado pelos meios de hospedagem para as mesmas? d) Esse destino obedece aos critérios de controle higiênico-sanitário? e) Quais sobras são consideradas como resíduos sólidos?
Essas contribuições e questões são importantes e merecem ser examinadas com profundidade pelos administradores dos meios de hospedagem, uma vez que a geração e o manejo de resíduos sólidos putrescíveis (originados de restos alimentares de origem animal e vegetal) está condicionada a controle e diferenciação das diversas sobras de alimentos.

Tabela 2. Distribuição de freqüências e porcentagens de indicações dos sujeitos sobre destino de pilhas, baterias, lâmpadas fluorescentes, seringas e medicamentos após consumo nos diferentes meios de hospedagem

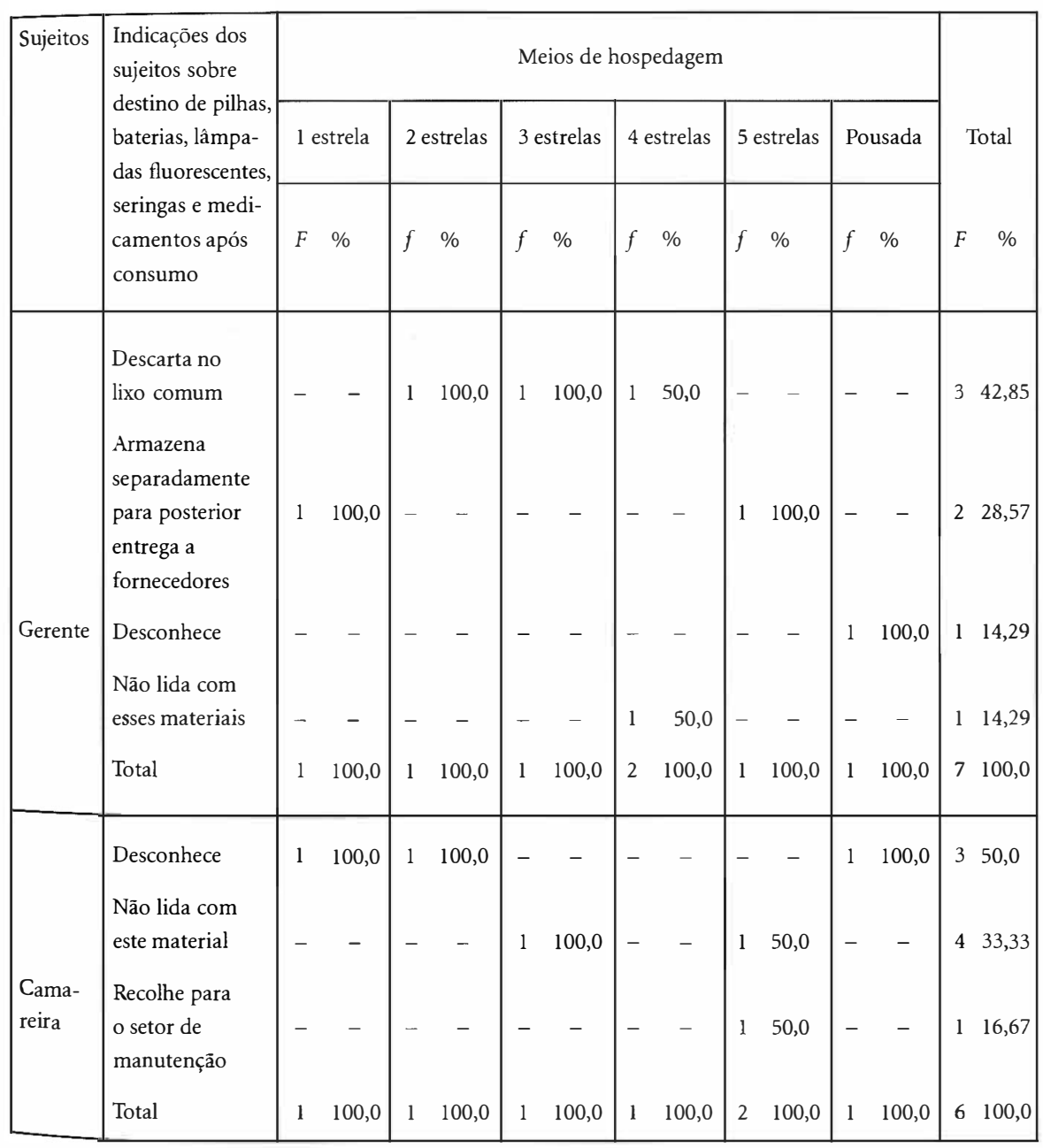

Fonte: Pesquisa de Campo (2003) 
De acordo com dados da Tabela 2, que apresenta a distribuição de freqüência e porcentagem de informação dos sujeitos sobre o destino de pilhas, baterias, lâmpadas fluorescentes, seringas e medicamentos, fica claro não existir, no âmbito dos meios de hospedagem, um cuidado referente ao descarte desses resíduos. Esses materiais são descartados juntamente com o resíduo orgânico $(42,85 \%$ de indicação entre os sujeitos-gerente dos hotéis duas, três e quatro estrelas). Seringas e medicamentos igualmente não dispõe de acondicionamento apropriado para descarte $(28,57 \%$ das indicações informam sobre a prática de armazenar esses resíduos para posterior entrega a fornecedores), 14,29\% das indicações referemse ao desconhecimento sobre o destino dado a esse tipo de resíduo e 14,29\% das indicações informam que os sujeitos não se deparam com esse tipo de resíduo no âmbito dos meios de hospedagem.

Entre os sujeitos-camareira, aparecem 50\% de indicações da informação "desconhecimento do destino dado a esses resíduos" nos hotéis uma estrela, duas estrelas e pousada. $33,33 \%$ das indicações referem-se a não lidar, no seu dia-adia, com esses resíduos. $16,67 \%$ das indicações indicam a prática de recolher esses resíduos pelo setor de manutenção.

Segundo D’Almeida e Vilhena (2000), qualquer material que possa pôr em risco a saúde do homem ou o meio ambiente é considerado perigoso. Entre esses materiais, são citadas pilhas e lâmpadas fluorescentes. Ainda de acordo com os autores, pilhas e lâmpadas fluorescentes estão presentes nos resíduos municipais em quantidades maiores em relação a outros resíduos potencialmente perigosos. Elas são consideradas resíduos perigosos por conterem metais pesados que podem migrar e integrar-se à cadeia alimentar humana. Nesse sentido, também cabe ressaltar as contribuições de Tchobanoglous (1993) sobre resíduos perigosos que, segundo esse autor, podem apresentar-se no estado sólido, semi-sólido ou líquido, e conter componentes altamente prejudiciais à saúde do homem. $\mathrm{O}$ autor cita, entre outros, o níquel e o cádmio, presentes na composição de pilhas e baterias. Também Schvartsman (1988) alerta para produtos que oferecem riscos toxicológicos ao homem e que são utilizados no âmbito de residências.

Convém destacar que a responsabilidade pela produção e pelo destino dos resíduos é da fonte geradora, conforme a Lei no 9.121 (Rio Grande do Sul, 1993). Nesse sentido, cabe aos administradores dos meios de hospedagem analisar a Le e adequar-se a ela, iniciando programas de manejo e gerenciamento específicos para resíduos potencialmente perigosos.

A partir do momento em que a fonte geradora assume suas responsabilidades pela produção e pelo destino dos resíduos sólidos que produz, é possível que se possa minimizar a geração dessa categoria de resíduos, contribuindo, dessa maneira, para o desenvolvimento de uma maior responsabilidade ambiental.

\section{Programas de Gerenciamento de Resíduos Sólidos nos Meios de Hospedagem}

Cabe destacar que os sujeitos foram questionados sobre a existência de programas de gerenciamento de resíduos sólidos nos meios de hospedagem. As respostas deixam claro que os meios de hospedagem, exceto um, não adotam nenhum tipo de programa de responsabilidade ambiental. Somente um sujeito do hotel cinco estrelas afirma a existência de programa de gerenciamento de resíduos sólidos.

Com relação a participar de programas de responsabilidade ambiental, os sujeitos demonstram interesse, com exceção do gerente do meio de hospedagem uma estrela, que indica não ter interesse por considerar o perfil do Programa Hóspedes da Natureza não adequado à realidade da categoria de seu hotel.

De acordo com Rodrigues (2002) e Castelli (1992), a base da oferta existente da indústria hoteleira no Brasil é formada por hotéis de pequeno e médio porte, freqüentemente de propriedade familiar, tendo sido a construção destes meios de hospedagem efetuada, em sua maioria, com a finalidade de ter um imóvel gerador de renda, mas atendendo igualmente a satisfações pessoais.

Ainda segundo os autores, analisando o histórico do desenvolvimento da indústria hoteleira brasileira, a construção de um hotel contém um forte componente emocional e de status. Muitos hotéis foram construídos, no Brasil, com o intuito de resolver problemas de herança e sucessão familiares. Somente no início da década de 1970, com a vinda das cadeias internacionais, a hotelaria brasileira passou a ser desenvolvida com bases mais profissionais, deixando de atender às necessidades pessoais de seus proprietários e buscando atender as necessidades dos seus clientes.

No que tange à adoção de programas de responsabilidade ambiental e gerenciamento de resíduos sólidos, indaga-se: essa tendência à falta de profissionalismo poderia explicar a razão pela qual os meios dehospedagem de Canela, todos de estrutura familiar, ainda não os adotarem? A ausência da concorrência de grandes cadeias internacionais, com programas ambientais bem desenvolvidos, poderia explicar essa inércia?

Abreu (2001) alerta para o advento de um novo tipo de hóspede: "os ilustres hóspedes verdes", que dão título à sua obra. Esse tipo de hóspede, atento à necessidade da prática de um turismo mais sustentável, vem mudando sua atitude em relação ao meio ambiente e exigindo práticas ambientalmente mais saudá- 
veis no âmbito dos meios de hospedagem. Além disso, segundo o autor, os cuidados com o meio ambiente acabam sendo um fator decisivo para a escolha entre um ou outro hotel.

Diante dessas colocações, e frente à necessidade dos meios de hospedagem assumirem suas responsabilidades frente aos resíduos sólidos que geram em suas atividades, é necessário que os mesmos iniciem um processo de desenvolvimento de planos de gerenciamento desses resíduos, no sentido de desencadear seus programas de responsabilidade ambiental. Os meios de hospedagem, assim como as indústrias e os hospitais, também necessitam de um programa de gerenciamento de resíduos sólidos. Em municípios turísticos, esses programas devem estar em sincronia com sistemas de coleta, tratamento e disposição final adotado nos mesmos.

\section{Considerações finais}

Os dados aqui expostos apresentam uma parte, ainda limitada, da situação de manejo de resíduos sólidos gerados no âmbito dos meios de hospedagem. Mas apontam para uma análise, uma reflexão e uma mudança de condutas que os agentes responsáveis por esses meios devem desenvolver em relação aos serviços que realizam e aos resíduos resultantes dos mesmos. Assim, é importante que os meios de hospedagem assumam suas responsabilidades pela geração dos resíduos sólidos; desenvolvam um ambiente adequado para a segregação, acondicionamento e armazenamento dos resíduos; insiram programas de sensibilização dos funcionários para problemas relacionados aos resíduos sólidos e ao meio ambiente.

É necessário lembrar a responsabilidade e a competência que os meios de hospedagem possuem sobre a geração de resíduos sólidos gerados em suas atividades, como também sobre o seu destino (Rio Grande do Sul, 1993). O fato de colocar o resíduo sólido na via pública para que o município colete e transporte para um sistema de tratamento, não isenta de responsabilidade a fonte geradora. Assim, todos os meios de hospedagem precisam ter clareza de suas atividades e dos produtos resultantes das mesmas, nunca esquecendo que os resíduos sólidos são um deles.

Se gerar resíduos é inerente às atividades desenvolvidas nos meios de hospedagem, os responsáveis pelos mesmos deverão sempre contabilizar a sua produção. Como decorrência, é importante que sejam contabilizados sistemas corretos de acondicionamento e armazenamento quanto aos espaços (local projetado para abrigar provisoriamente os resíduos sólidos); sistemas de acondicionamento e estocagem na via pública, no sentido de atender às características dos resíduos e a periodicidade da coleta dos mesmos; sistemas de transporte; tratamento; disposição final.
No sentido de minimizar a quantidade de resíduos sólidos gerada nos meios de hospedagem, também é necessário que os mesmos desenvolvam alternativas tecnológicas a serem aplicadas no âmbito da fonte geradora, por exemplo, a realização de compostagem de resíduos orgânicos (restos alimentares e resíduos da limpeza de jardins) voltada para suprir necessidades de composto orgânico do próprio meio de hospedagem (hortas e jardins). É importante que cada um desses meios disponha de um gerente ambiental, incumbido de coordenar as diferentes atividades relacionadas à implantação, monitoramento e aperfeiçoamento desses programas.

Como decorrência dos resultados apresentados, recomenda-se que haja continuidade no processo de levantamento das situaçōes de manejo de resíduos sólidos gerados no âmbito dos meios de hospedagem de Canela; e que novos meios de hospedagem sejam selecionados e investigados, especialmente hotéis de categoria uma estrela e pousadas, que representam o maior número de meios de hospedagem.

É importante conduzir pesquisas, também, junto aos hóspedes, identificando a percepção ambiental, as informações sobre o fenômeno dos resíduos sólidos, a preferência por meios de hospedagem com programas na área ambiental e as dificuldades relacionadas ao manejo de resíduos sólidos no âmbito desses meios. Esse tipo de investigação auxilia os meios de hospedagem e os municípios turísticos a construírem suas próprias políticas ambientais.

\section{Referências Bibliográficas}

ABREU, D. 2001. Os ilustres hóspedes verdes. Salvador: Casa da Qualidade.

ASSOCIAÇĀO BRASILEIRA DA INDÚSTRIA DE HOTÉIS - ABIH. 2001. Programa ABIH de responsabilidade ambiental hóspedes da natureza. Porto Alegre: ABIH-RS.

ASSOSSIAÇĀO BRASILEIRA DE NORMAS TÉCNICAS - ABNT. 1987. NBBR 10.004: Resíduos sólidos - Classificação. Rio de Janeiro: ABNT.

CASTELLI, G. 1992. Administração hoteleira. Caxias do Sul: EDUCS.

D’ALMEIDA, M. L.;VILHENA, A. 2000. Lixo municipal: manual de gerenciamento integrado. 2.ed. São Paulo: IPT/Cempre.

GOELDNER,C. R.; RITCHIE, B.; McINTOSH,R.W. 2002. Turismo: princípios, práticas e filosofias. 8. ed. Porto Alegre: Bookman.

IGNARRA, L. R. 2001. Fundamentos do turismo. São Paulo: Pioneira Thompson Learning. INSTITUTO BRASILEIRO DE TURISMO - Embratur; INMETRO. 1998. Regulamento e matriz de classificação dos meios de hospedagem e turismo. Deliberação Normativa no 387 de 28/01/1998. São Paulo: Suprimentos e Serviços. 
INSTITUTO BRASILEIRO DE GEOGRAFIA E ESTATÍSTICA - IBGE. Pesquisa Nacional do Saneamento Básico. Disponivel em: <http://www.ibge.gov.br>. Acesso em 14 jun. 2003.

LAMPRECHT, J.; RICCI, R. 1997. Padronizando o sistema da qualidade na hotelaria mundial. Rio de Janeiro: Qualitymark.

LIMA, L. M. Q. 1995. Lixo: tratamento e biorremediação. São Paulo: Hemus.

MANDELLI, S. M. C. Variáveis que interferem no comportamento da população urbana no manejo de resíduos sólidos domésticos no âmbito das residências. 1997. Tese (Doutorado Educação) - Universidade Federal de São Carlos, São Carlos.

MOLINA, E. S. 1998. Turismo y ecología. 6. ed. México: Trillas.

RIO GRANDE DO SUL. s.d. Lei n 9.121, de 27 de julho de 1993. Dispõe sobre a gestão dos resíduos sólidos, nos termos do artigo 247, parágrafo $3^{\circ}$ da Constituição do Estado e dá outras providências. Porto Alegre: FEPAM.

ROCHA, C. C.; JUNCO, J. G.; GONZÁLEZ, F. J. 2000. Organización y gestión de empresas turísticas. Madrid: Pirámide.

RODRIGUES, R. Histórico do desenvolvimento de hotéis no Brasil. Disponível em: <http:// www.hia.com>. Acesso em 10 jun. 2003.

RUES, E. 1995. Eco-hotel management: conciencia ecológica en la administración hotelera. México: Grupo Editorial Iberoamérica.

SCHVARTSMAN, S. 1980. Produtos químicos de uso domiciliar: segurança e riscos toxicológicos. São Paulo: Almid.

SILVA JUNIOR, E. A. 1995. Manual de controle higiênico-sanitário em alimentos. São Paulo: Livraria Varela.

SWARBROOKE, J. 2000. Turismo sustentável: conceitos e impactos a mbientais. São Paulo: Aleph.

TCHOBANOGLOUS, G.; THEISEN, H.; VIGIL, S. 1993. Integrated solid waste management: engineering principles and management issues. [s/l]: McGraw Hill.

Recebido em 13/08/2003 ( $1^{\text {a }}$ versão) e 06/10/2003 (2a versão).

Aprovado com alteraçôes em 23/09/2003 e aprovação final 